\title{
Grande sertão: veredas, um inventário da avifauna
}

\author{
[ "Grande sertão: veredas", a commented birdlife inventory
}

\section{Willian Dolberth ${ }^{\mathrm{x}}$}

Klaus F. W. Eggensperger ${ }^{2}$

RESUMO - O presente trabalho se propõe a inventariar as aves citadas no romance Grande sertão: veredas, classificando seus usos e traçando um panorama do processo criativo que as levou até as páginas do livro. Nosso objetivo é desvelar a natureza da representação da avifauna na obra, uma alternativa de leitura ecologicamente consciente que se opõe à perspectiva antropocêntrica que retrata os elementos da natureza de forma opaca e pitoresca. Acreditamos que uma abordagem ecocrítica nos permite reconhecer novos aspectos do complexo processo de criação rosiano, um amálgama de ciência natural e cultura popular originando uma mimese da natureza que fecunda diversos outros motivos dentro da obra. PALAVRASCHAVE - Ecocrítica; avifauna; Guimarães
Rosa. - ABSTRACT - The present paper aims to inventory the birds mentioned in the novel “Grande sertão: veredas", classifying them and tracing a panorama of the creative process that brought them to the pages of the book. Our goal is to unveil the nature of the avifauna representation in the work, an ecologically conscious reading alternative in opposition to the anthropocentric perspective that treats the natural elements in an opaque and picturesque way. We believe that an ecocritical approach allows us to recognize new aspects of the complex rosian creation, an amalgam of natural science and popular culture originating a mimesis of nature that fecundates several other motifs within the work. - KEYWORDS - Ecocriticism; birdlife; Guimarães Rosa.

Recebido em 7 de agosto de 2019

Aprovado em 23 de fevereiro de 2020

EGGENSPERGER, Klaus F. W.; DOLBERTH, Willian. Grande sertão: veredas, um inventário da avifauna. Revista do Instituto de Estudos Brasileiros, Brasil, n. 75, p. 53-70, abr. 2020.

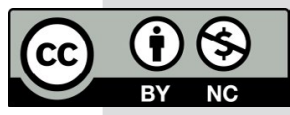

DOI: http://dx.doi.org/Io.II6o6/issn.23I6-90IX.voi75p53-70

I Universidade Federal do Paraná (UFPR, Curitiba, PR, Brasil).

2 Universidade Federal do Paraná (UFPR, Curitiba, PR, Brasil). 


\title{
O INVENTÁRIO
}

\author{
Uma anhuma rasou por cima de nós \\ tocando fagote. Eu disse para o Rosa \\ ouvir: o canto desse pássaro diminui a \\ manhã. Rosa pôs tento. Ele tinha uma \\ sede anormal por frases com ave.
}

(BARROS, 1994, p. 19).

Para um observador de aves, a leitura do Grande sertão: veredas representa uma experiência análoga ao caminhar num território silvestre. Em meio a um diálogo ou no devaneio de uma travessia é possível que uma vocalização furtiva arrebate completamente a atenção; sendo ela naturalmente sinestésica, um chamado penado, suscita uma memória ecológica buscando reconhecer o emissor, sua localização, a intenção de seu chamado e, no caso da literatura, a ligação desses elementos precedentes com os demais elementos da narrativa. As autoras Durães (I999) e Meyer (20I7) ressaltam a importância dessa relação entre a dimensão ecológica e outros temas presentes no romance rosiano, indicando que o mundo natural não está apartado dos outros motivos, uma vez que ele não se manifesta "como um palco, cenário ou moldura onde se desenrola a ação [...]. A narrativa é construída de modo que a realidade humana se entrelace com o mundo natural de tal forma que a identidade de cada um seja o resultado de uma relação de reciprocidade" (MEYER, 20I7, p. 28). A partir dessa perspectiva, quando identificamos as aves dentro do romance nós damos um passo em direção ao conhecimento holístico do sertão, dado que "esta é a lei da natureza: nada está fechado em si, ou isolado, tudo na natureza está relacionado entre si” (DURÃES, I999, p. I68).

No Grande sertão: veredas há uma recorrência notável de vocábulos descritivos e nominativos de origem ecológica, dentre os quais se encontram as aves; estes 
são tradicionalmente deixados de lado na maioria das pesquisas que tematizam a obra. De acordo com Meyer (20I7, p. 34), "um levantamento dos estudos sobre a obra de Guimarães Rosa aponta um volume pequeno de trabalhos vinculados ao tema 'natureza', que na maioria das vezes não se constitui em eixo central da reflexão". Mas essa invisibilidade da natureza, tal como apontada por Meyer, não se restringe ao romance rosiano, pois segundo a ecocrítica ela é igualmente válida para inúmeras outras manifestações culturais.

De acordo com Fromm, a inexperiência ecológica moderna é visível nos membros mais novos da espécie, uma vez que "para a criança comum dos Estados Unidos nos dias de hoje, a natureza é de fato um grande mistério, não na medida em que é incompreensível, mas na medida em que é praticamente inexistente em suas percepções”3 (FROMM, I978, p. 33 - tradução nossa). Já Manes argumenta que a incapacidade de perceber a natureza na modernidade é viabilizada pela nossa linguagem, a qual silencia os elementos naturais, tornando o discurso, instrumento do poder, uma prerrogativa exclusivamente humana. Esse monopólio linguístico opõe-se às sociedades animistas ou de caçadores-coletores, que admitiam o discurso dos animais, das plantas e até dos minerais que, para eles, produziam discursos inteligíveis e essenciais como elementos de sobrevivência, coesão social e cosmológica (MANES, I992, p. I5).

O reconhecimento do processo milenar de dissimulação da natureza nas culturas humanas é muito importante para este trabalho, mas não é o nosso foco; em vista disso não nos aprofundaremos mais neste assunto que, oportunamente, nos serve de ponte para justificar nossa escolha de recorte. Escolhemos a avifauna como representativa da riqueza ecológica do romance analisado partindo da premissa de que as aves, mesmo esmaecidas pelo processo moderno de ocultação da natureza, são privilegiadas em relação a outros animais e vegetais por uma série de fatores.

Segundo Tüür, dentre os animais que se relacionam diretamente com o homem, a classe das aves é, provavelmente, a mais popular no que se refere à apreciação estética. A autora justifica sua afirmação ao expor a larga distribuição geográfica da classe, presente nos sete continentes, demonstrando também a facilidade da observação que pode ser feita em conjunto com outras atividades (almoçar, arar etc.) e o seu apelo multissensorial, que separa a avifauna de outras classes como as borboletas e os peixes ornamentais, que, apesar de possuírem um grande apelo visual, não vocalizam. As aves diferenciam-se desses também por suas estruturas epidérmicas estimadas pelos homens, as penas, que produzem uma sensação mais amistosa quando comparadas com escamas de peixe ou asas de borboleta (TÜÜR, 2009, p. 58).

Contudo, sabemos que, apesar de privilegiada, a apreciação estética das aves não é muito difundida na modernidade. De praxe, no mundo fenomenológico, o interesse dispensado às aves é visto como trivial quando compartilhado fora do círculo entusiasta do observador, prática que se repete na observação de aves na literatura. Felizmente a literatura é uma arte dialógica e, ao lermos Grande sertão: veredas, encontramos um interlocutor experiente e carismático que compartilha conosco a riqueza de suas observações.

3 No original: "To the average child of the United States in the present day Nature is indeed a great mystery, not insofar as it is incomprehensible but insofar as it is virtually nonexistent to his perceptions". 
Quem transpõe Grande sertão: veredas é guiado por um protagonista que paira os olhos no céu e aguça os ouvidos na mata, e o que ele vê e ouve é utilizado para traduzir uma infinidade de informações, por vezes essenciais, ligadas ao fio condutor da narrativa. A compreensão desse idioleto exige do viajante um conhecimento ecológico prévio ou a dedicação para obter novos conhecimentos durante a travessia, o que é fundamental para acessar o imo do texto. Afinal de contas, como afirma o próprio sertanejo: "não narrei nada à-tôa: só apontação principal, ao que crer posso. Não esperdiço palavras” (ROSA, I956, p. 305)4.

Para o reconhecimento e refinamento desse inventário consultamos algumas obras influentes da ornitologia brasileira, como Sick (200I), Santos (I979) e Descourtilz (I983), utilizados para verificar nomes populares e também algumas relações etno-ornitológicas. Além disso, consultamos Sigrist (2014) e Van Perlo (2009) para apurar a distribuição geográfica de algumas espécies. As aves que ocorrem no sertão entre Minas Gerais, Goiás e Bahia com denominações amplamente reconhecidas ou com denominações populares identificadas foram adicionadas ao inventário. É interessante notar que nenhuma das espécies escolhidas por Rosa encontra-se fora de seu bioma, todas estão cuidadosamente espalhadas numa paisagem que respeita o princípio da verossimilhança ecológica.

Boa parte das aves citadas no romance denominam personagens e localidades, mas existem também novos verbos e interjeições inspirados na avifauna. Além da representação dentro da representação nós gostaríamos de atentar para a relação direta dos personagens com as aves; para esse fim nos foi necessário realizar uma distinção de usos da avifauna na obra através de um inventário fragmentado, considerando as citações conotativas (localidades, personagens, flora, verbos e interjeições) e as denotativas (aves específicas e genéricas).

No que se refere à relação denotativa, há a nosso ver duas formas de interação entre o homem e a avifauna no sertão rosiano: a apreciação estética, diretamente relacionada às qualidades femininas, e a relação pragmática, referente às práticas masculinas. A primeira relação se manifesta no contato inicial entre Riobaldo e Diadorim, ainda na infância, no de-Janeiro, onde ocorre a primeira experiência do narrador com a contemplação ativa dos elementos naturais:

Um pássaro cantou. Nhambú? E periquitos, bandos, passavam voando por cima de nós. Não me esqueci de nada, o senhor vê. Aquele menino, como eu ia poder deslembrar? Um papagaio vermelho: - “Arara for?” - ele me disse. E - quê-quê-quê? - o araçarí perguntava. (ROSA, I956, p. I04-IO5).

Aprendizado que seria retomado anos mais tarde no Rio das Velhas:

Até aquela ocasião, eu nunca tinha ouvido dizer de se parar apreciando, por prazer de enfeite, a vida mera deles pássaros, em seu começar e descomeçar dos voos e pousação. Aquilo era para se pegar a espingarda e caçar. Mas o Reinaldo gostava: - "É formoso próprio...” - ele me ensinou. (ROSA, I956, p. I43).

4 Em todas as transcrições foi mantida a grafia original. 
Ocasião na qual o já crescido narrador constataria a estranheza da apreciação estética das aves praticada por dois homens: "Mas o dito, assim, botava surpresa. E a macieza da voz, o bem-querer sem propósito, o caprichado ser - e tudo num homem-d'armas, brabo bem jagunço - eu não entendia! Dum outro, que eu ouvisse, eu pensava: frouxo, está aqui um que empulha e não culha” (ROSA, I956, p. I43-I44).

Herdada de Diadorim, a sensibilidade em relação às aves é assimilada e reproduzida por Riobaldo durante toda a narrativa, considerando que o relato tem caráter introspectivo: "O senhor é de fora, meu amigo mas meu estranho. Mas, talvez por isto mesmo. Falar com o estranho assim, que bem ouve e logo longe se vai embora, é um segundo proveito: faz do jeito que eu falasse mais mesmo comigo" (ROSA, I956, p. 40-4I).

As observações são raramente compartilhadas com outros homens, sendo só Diadorim: "Era mês de macuco ainda passear solitário - macho e fêmea desemparelhados, cada um por si. E o macuco vinha andando, sarandando, macucando: aquilo ele ciscava no chão, feito galinha de casa. Eu ri - 'Vigia este, Diadorim!' - eu disse" (ROSA, I956, p. 286-287).

Otacília e algumas crianças que partilham dessa apreciação:

Aquela visão dos pássaros, aquele assunto de Deus, Diadorim era quem tinha me ensinado. Mas Diadorim agora estava afastado, amuado, longe num emperreio. Principal que eu via eram as pombas. No bebedouro, pombas bando. E as verdadeiras, altas, cruzando do mato. - "Ah, já passaram mais de vinte verdadeiras..." - palavras de Otacília, que contava. (ROSA, I956, p. 189).

Esses meninozinhos, todos, queriam todo o tempo ver nossas armas, pediam que a gente desse tiros. Diadorim gostava deles, pegava um por cada mão, até carregava os menorzinhos, levava para mostrar a eles os pássaros das ilhas do rio. - "Olha, vigia: 0 manuelzinho-da-crôa já acabou de fazer a muda...”. (ROSA, I956, p. 289).

Já a relação pragmática com as aves se estabelece em diversos níveis, como dietético, representado pela caça das aves nativas pertencentes à família dos tinamídeos, como a perdiz (Rhynchotus rufescens): "Senhor caça? Tem lá mais perdiz do que no Chapadão das Vertentes...” (ROSA, I956, p. 28); “Aí mais, quando tornei a rever Diadorim, constante vi, que andava à minha espera com os companheiros, num papuã, matando perdizes" (ROSA, I956, p. 5I8).

A codorna (Nothura maculosa): "Dias inteiros, nada, tudo o nada - nem caça, nem pássaro, nem codorniz” (ROSA, I956, p. 33I). O inhambu (Crypturellus sp.): "Zé Bebelo disse, depois de derrubar o tal, com um tiro de nhambu, baixo" (ROSA, I956, p. 96). O macuco (Tinamus solitarius): "O macuco me olhou, de cabecinha alta. Ele tinha vindo quase endireito em mim, por pouco entrou no rancho. Me olhou, rolou os olhos. Aquele pássaro procurava o quê? Vinha me pôr quebrantos. Eu podia dar nele um tiro certeiro. Mas retardei. Não dei” (ROSA, I956, p. 287).

Também há a alimentação proporcionada pela avicultura, aplicável no sertão através de espécies exóticas como a galinha (Gallus gallus domesticus) e a galinha-d'angola (Numida meleagris): 
O que esse menino babeja vendo, é sangrarem galinha [...]. (ROSA, I956, p. I5);

A saudade minha maior era de uma comidinha guisada: um frango com quiabo e abóbora-d’água e caldo [...]. (ROSA, I956, p. I68);

Onde tive os usuais agrados, com regalias de comida em mesa. Sendo que galinha e carnes de porco, farofas [...]. (ROSA, I956, p. 444);

[...] hóspede de seo Josafá Ornelas. Tomei caldo-de-galinha, deitado em lençóis alvos, recostado. (ROSA, I956, p. 588);

Pergunto: - "Zé-Zim, por que é que você não cria galinhas-d'angola, como todo o mundo faz?”. (ROSA, I956, p. 43);

Depois de tantas guerras, eu achava um valor viável em tudo que era cordato e correntio, na tiração de leite, num papudo que ia carregando lata de lavagem para o chiqueiro, nas galinhas d’angola ciscando às carreiras no fedegoso-bravo [...]. (ROSA, I956, p. I88).

Além do aspecto nutricional, a avifauna é tradicionalmente empregada pelos jagunços como marcador temporal: "o dia vindo depois da noite - esse é o motivo dos passarinhos” (ROSA, I956, p. 480). Ademais, aves são vistas como indicadores ecológicos quando chegam, partem ou mesmo quando não estão presentes;

Mas o curralão já estava pendurado de urubus, os usos como eles viajam de todas as partes, urubu, passarão dos distúrbios. (ROSA, I956, p. 346-347);

Pássaro pousado em moita, que se assusta forte a voo, dá aviso ao inimigo. Pior são os que têm ninho feito, às vezes esvoaçam aos gritos, no mesmo lugar - dão muito aviso. (ROSA, I956, p. 204);

Nas lagoas aonde nem um de asas não pousa, por causa da fome de jacaré e da piranha serrafina. (ROSA, I956 p. 33);

[...] Liso do Suçuarão, é o mais longe - pra lá, pra lá, nos ermos. Se emenda com si mesmo. Água, não tem. [...] Não tem excrementos. Não tem pássaros. (ROSA, I956, p. 36).

O conhecimento de sua vocalização também é utilizado em casos de necessidade: "Abarcamos as condições do lugar, em cerco, entendidos uns com uns, por meio de avisos: que eram canto de acauã" (ROSA, I956, p. 504).

Reconhecendo os devidos usos e levando em conta a menção às aves específicas e genéricas, fizemos duas leituras integrais do fac-símile da primeira edição do romance publicado em I956, assinalando todas as ocorrências encontradas com o intuito de elaborar um inventário que expusesse a avifauna observada e que permitisse uma análise do material identificado. 


\section{Aves específicas $^{5}$}

acauã - Herpetotheres cachinnans (p. 504)

anú-branco - Guira guira (p. 99)

araraúna [arara-canindé] - Ara ararauna (p. 456)

azulêjo [chupim] - Molothrus bonariensis (p. 31)

bem-te-vi - Pitangus sulphuratus (p. 30, 34)

birro [pica-pau-branco] - Melanerpes candidus

(p. 197, 311)

caboclo-d'água [mãe-da-lua-gigante] - Nycti-

bius grandis (p. 106)

caboré [caburé] - Glaucidium brasilianum (p.

412)

cãcã [cancão] - Ibycter americanus (p. 300)

codorniz [codorna-amarela] - Nothura maculo$s a$ (p. 311)

doidinha - Elaenia sp. (p. 29)

ema - Rhea americana (p. 310, 406, 529)

fariscadeira - Columbidae sp. (p. 34)

fôgo-apagou - Columbina squammata (p. 188)

galinha - Gallus gallus domesticus (p. 15, 49, 258, 287, 392, 444, 445, 510, 588); pinto (p. 49, 104, 311); frango (p. 168); galo (p. 217, 394); garnizé (250)

galinha-d'angola - Numida meleagris (p. 43, 188) gangorrinha [canário-do-mato] - Myiothlypis flaveola (p. 29)

garrixo [corruíra] - Nothura maculosa (p. 311)

garricha-do-brejo [curutié] - Certhiaxis cinnamomeus (p. 30); garrixa-do-brejo (p. 282)

garça-rosada [maria-faceira] - Syrigma sibilatrix (p.575)

gavião-andorim [gavião-tesoura] - Elanoides forficatus (p. 49)

graúna - Gnorimopsar chopi (p. 34); passoprêto (p. 480)

grunhatá-do-coqueiro [cambacica] - Coereba flaveola (p. 30)

guaxe-Cacicus haemorrhous (p. 352)

jesus-meu-deus [tico-tico-de-bico-preto] - Arremon taciturnus (p. 197)

5 Nesta e nas próximas seções os termos estão grafados conforme se encontram nas páginas referenciadas. joão-de-barro - Furnarius rufus (p. 22)

joão-pobre - Serpophaga nigricans (p. 286) juriti-do-peito-branco [juriti-pupu] - Leptotila verreauxi (p. 34)

macuco - Tinamus solitarius (p. 28, 286, 287) mãe-da-lua - Nyctibius griseus (p. 194, 195, 395, 520)

manuelzinho-da-crôa [batuíra-de-coleira] -

Charadrius collaris (p. 143, 144, 283, 289, 307, 350, 457, 507, 575); manuelzinho (p. 575) martim-pescador - Alcedinidae sp. (p. 143) mergulhão - Podicipedidae sp. (p. 143) nhaúma [anhuma] - Anhima cornuta (p. 145, 457)

papa-banana [japu] - Psarocolius decumanus (p. 30); joão-congo (p. 519) pato-prêto [pato-do-mato] - Cairina moschata (p. 47, 143) pato-verde-Anatidae sp. (p. 143) peitica - Empidonomus varius (p. 209) perdiz - Rhynchotus rufescens (p. 28, 518) perú - Meleagris gallopavo (p. 255) pomba-bando [avoante] - Zenaida auriculata (p. 189)

pomba-verdadeira [asa branca] - Patagioenas picazuro (p. 189)

pomba-vermelha-do-mato-virgem [juriti-vermelha] - Geotrygon violacea (p. 34) poví [fim-fim] - Euphonia chlorotica (p. 29) pintassilgo - Spinus magellanicus (p. 303) quem-quem - Cyanocorax cyanopogon ( $\mathrm{p}$. 286, 396)

rexenxão [iraúna-grande] - Molothrus oryzivorus (p. 283)

rôla-vaqueira - Uropelia campestris (p. 29) sabiá-ponga [sabiá-laranjeira] - Turdus rufiventris (p. 30) sabiá-preto [sabiá-una] - Turdus flavipes (p. 311)

saci-do-brejo [japacanim] - Donacobius 
atricapilla (p. 29)

sebastião/tabaco-bom [corucão] - Podager

nacunda (p. 202)

seriema - Cariama cristata (p. 142, 195, 310, 512)

socó-boi - Tigrisoma lineatum (p. 291)

suindara - Tyto furcata (p. 94, 395)

suiriri - Tyrannus melancholicus (p. 30) tempo-quente [saci] - Tapera naevia (p. 29); saci (p. 235)

tirirí - Furnariidae sp. (p. 34, 209)

trinca-ferro - Saltator similis (p. 431)

xenxém [marreca-caneleira] - Dendrocygna bicolor (p. 29)

zabelê [jaó-do-sul] - Crypturellus noctivagus (p. 311)

\section{Aves genéricas}

andorinha (p. 71, 310)

arara (p. 53, 105, 371, 376, 431, 456)

araras (p. 30, 46, 304, 309, 353)

araçari (p. 105)

aves (p. 48)

bacurau (p. 510)

bacuraus (p. 202)

beija-flôr (p. 338, 482)

coruja (p. 202, 244, 394, 413, 476, 495, 511)

corujão (p. 493)

corujinha (p. 495)

côrvo (p. 13)

curiango (p. 203)

frangos-d'água (p. 282)

gaivota (p. 562)

gaivotas (p. 282)

galinhol (p. 575)

garças (p. 47, 283, 291, 585)

garça-branca (p. 575)

gavião (p. 13, 143, 244, 259, 283, 310, 366,

$320,530,550,559,562)$

gaviãozinho (p. 366, 523)

jaburú (p. 241, 575)

jaburús (p. 47, 143)

jacús (p. 244)

jaós (p. 458)

maracanãs (p. 193)

marrecos (p. 47)

marrecas (p. 427)

marrequinhos (p. 143)

marrequim (p. 282)

nhambú (p. 96, 104)

papagaio (p. 56, 98, 105, 257)

papagaios (p. 366, 405)

passarinho (p. 15, 30, 157, 372, 415, 557, 575)

passarinhos (p. 52, 175, 208, 392, 407, 416, 480, 484, 557)

pássaro (p. 30, 49, 53, 62, 104, 144, 181, 204, 235, $283,287,311,313,415,435,457,507,550,555)$

pássaros (p. 28, 34, 36, 42, 43, 47, 48, 53, 54, 60, $66,94,132,143,148,189,202,205,282,289$, $307,313,314,374,388,395,442,523,530,539$,

$562,565,575)$

passarão (p. 347)

patos (p. 143)

periquitos (p. 104, 309)

pica-pau (p. 260, 286, 500)

pombo (p. 372, 385)

pombas (p. 189)

sabiá (p. 235, 299)

socó (p. 291)

tucano (p. 491)

tucanos (p. 311)

um de asas (p. 33)

urubú (p. 332, 346, 375, 430, 477, 530, 546, 562)

urubús (p. 49, 97, 143, 290, 346, 347, 350, 374,

456)

urutau (p. 548) 


\section{Localidades}

Arassuaí (p. 62)

Chapada-da-Seriema-Correndo (p. 248)

Coruja (p. 394, 395, 399, 404)

Corujeiras (p. 35)

Fazenda dos Tucanos (p. 317, 325, 352, 369, 476);

Tucanos (p. 318, 319, 401); Casa dos Tucanos (p. 338, 348); fazenda-grande dos Tucanos (p. 365)
Pôrto-Passarinho (p. 591, 592)

Quem-Quem (p. 282)

Serra das Araras (p. 35)

Serra do Urubú do Indaiá (p. 306)

Tuim (p. 587)

Várzea da Ema (p. 36)

Urubú (p. 112, 119, 305)

Uruú (p. 514)

\section{Verbos, substantivos, adjetivos, interjeições}

papagaiagem (p. 91)

periquitava (p. 93)

galinholagem (p. 143)

corujante (p. 520)

beija-florou (p. 576)
Ave (p. 15, 69, 331)

av'ave! (p. 569)

ave-mariazinha (p. 142)

ave-marias (p. 245, 386)

\section{Personagens}

Acauã (p. 25, 92, 164, 167, 315, 321, 362, 364 , 377, 379, 429, 457, 466, 541, 582, 587)

Federico Xexéu (p. 237)

Gavião-Cujo (p. 291, 292, 293, 294)
João Concliz (p. 26, 86, 87, 91, 92, 93, 96, 97 , 314, 321, 322, 357, 364, 372, 440, 444, 496, 521, 526, 532, 551, 583, 594, 587)

João-Curiol (p. 248, 249, 250, 251, 571, 582, 583, 584, 587)

Pé-de-Pato (p. 41, 297)

\section{Flora}

araçá-de-pomba (p. 208)

canela-de-ema (p. 33, 512) pau-pombo (p. 108, 499)

rabo-de-galo (p. 193) 


\section{O PROCESSO DE CRIAÇão}

Você conhece meus cadernos. Quando saio montado num cavalo, pela minha Minas Gerais, vou tomando nota das coisas. $O$ caderno fica impregnado de sangue de boi, suor de cavalo, folha machucada. Cada pássaro que voa, cada espécie, tem voo diferente. Quero descobrir o que caracteriza o voo de cada pássaro, a cada momento.

Eu não escrevo difícil. EU SEI O NOME DAS COISAS ${ }^{6}$.

Um raro vislumbre do processo criativo de João Guimarães Rosa nos foi dado em $20 I I$ com a publicação, sob o título de $A$ boiada, das anotações feitas pelo autor durante uma travessia pelo sertão mineiro no ano de I952. Uma cursiva solta, digna de um sismógrafo, denuncia o balanço do lombo do animal de montaria nesse diário que mistura crônica narrativa, captação etnográfica e inventário ecológico. Era de imaginar que a publicação entusiasmaria novas leituras ambientalmente conscientes da obra, o que não se confirmou. Segundo Meyer (20I7), "Quanto aos pesquisadores que mencionam A boiada na produção de trabalhos acadêmicos, nenhum deles utilizou o material para estudo da natureza" (MEYER, 20I7, p. 39). É exatamente o que pretendemos fazer aqui, consoante a visão de Moreira (20I2, p. 240) de que "reduzir o localismo [...] a uma camada de verniz pitoresco sobre um miolo de valores universais ou ao uso de um mundo arcaico como um objeto improvável para aplicação de técnicas narrativas modernas é fazer de uma dimensão central da obra um mero maneirismo".

Uma leitura de Grande sertão: veredas orientada pelas indicações de $A$ boiada evidencia o processo de criação rosiano. Uma transmutação de signos fenomenológicos apreendidos e admirados pelo autor em signos literários profundos e dinâmicos. Por diversas vezes achamos paralelos quase idênticos às percepções imediatas originais:

No alto, eram muitas flores, subitamente vermelhas, de olho-de-boi e de outras trepadeiras, e as roxas, do mucunã, que é um feijão bravo; porque se estava no mês de maio, digo - tempo de comprar arroz, quem não pôde plantar. Um pássaro cantou. Nhambú?. (ROSA, 1956, p. 104).
No "Rio de Janeiro": As longas canoas. Sacos atados com broto (folha nova de buriti), cheia de sacos (com arroz: 15 alqueires) [...]. No mato margem direita: alto, nas árvores, abundantes, sempre as flores roxas do ôlho-de-boi: cipó (trepadeira). Canta um pássaro (Nhambú)? (ROSA, 2011, p. 39-40).

6 Depoimento de Guimarães Rosa a Pedro Bloch (apud RÓNAI, I983, p. 9I-92). 
Vindo na vertente, tinha o quintal, e o mato, com o garrulho de grandes maracanãs pousadas numa embaúba, enorme, e nas mangueiras, que o sol dourejava. (ROSA, 1956, p. 193).
Azuis longas núvens. (Zito): - Essa nuvem é nuvem de frio...

As grandes maracanãs na embaúba, enorme, e na mangueira, que o sol doira. (ROSA, 2011, p. 128).

Aqui há, além do reconhecimento de algumas espécies de flora, a menção geral de famílias de aves, como o nhambu (Crypturellus sp.) e as maracanãs (Psittacidae $s p$.). Não reconhecer o primeiro como uma galinha e o segundo como um papagaio já demonstra um interesse ecológico acima do habitual, o qual será confirmado com o refinamento dessas observações no caminhar da boiada através de análises morfológicas e bioacústicas da avifauna:

Vôa o casal de maria-tôla - pensei que fôssem anús. Pretas, o macho tem topete, do mesmo preto. Têm uma mancha clara sob cada asa. Passarinho arisco; pouco comum. É mais de campo. Não se aproxima de casas [...]. (ROSA, 20II, p. 27).

João-fazendeiro: passarinho cinzento. Mais escuro que o duro-vai. Fica nos campos. É menor que um duro-vai. É do tamanho de um pintassilgo. Gosta de fazer ninho nas laranjeiras. É um ninho redondo, só com um buraco pra ele entrar. (ROSA, 2OII, p. I57).

Nas gaiolas: o passarinho “cigarra”. É do sertão. Só vem aqui (na Vargem, em Cordisburgo) nas águas, para reproduzir. Depois que os filhotes estão voando, voltam para o sertão. Costas pretas, ventre e papo claros, com uma lista branca na cabeça. Tamanho de um canário. Canta mais bonito que um pintassilgo. (ROSA, 20II, p. I8I).

Às 6 hs. menos 5’ Já está claro. Cantores matinais: o canarinho é muito madrugador; papa-capim; pássaro-preto. Um gavião-pinhé. Ontem à noite: 2 ou 3 corujas, se raspando na estrada. Hoje, madruga: curiango. (ROSA, 20II, p. 3I).

Tem um passarinho de vereda - (do tamanho de uma juriti, um pouco menor, mas de bico comprido. É pardo, apedrezado, com umas pintas). Chama-se ÁGUA-SÓ. O canto é: tiriririri-chóo-chóo-chóo-agua só, agua só!... (reza-povo, reza-povo!... — outros dizem que é como ele canta). [...] Nas águas, quando está vesp’rando as águas, ele canta muito e sai para fora, até nos gerais; cantando então muito. Não canta de dia; de dia nem ninguém vê ele. Canta da boca da noite até à meia noite. Bonito ele não é. (ROSA, 20II, p. 43).

Um dos vaqueiros que o acompanhou numa boiada anterior, no Mato Grosso, deixou um relato sobre esse processo de inventário do autor, afirmando que Guimarães "tudo queria saber: os nomes dos pássaros, dos pés de folha, o nome das vacas. Não largava o caderninho, nem nos rodeios. [...] Uma vez pediu para 
eu responder se urubu sentia frio"7. Dessa mistura de ciência natural e abstração empírica surgiram algumas formulações abstratas provenientes do material coletado na viagem:

Maiores vezes, ainda fico pensando. Em certo momento, se o caminho demudassese o que aconteceu não tivesse acontecido? Como havia de ter sido a ser? Memórias que não me dão fundamento. O passado - é ossos em redor de ninho de coruja... (ROSA, I956, p. 5II).
Coruja - A coruja pequena, batuqueira, não faz ninhos. Põe ovos no cupim, ou em buraco de tatú. Elas gostam de ficar na porta - no buraco de cupim. Quando a gente passa, ela dá um grito feio - um barulho de chiata: cuîc cc' kikikik! - e entra no buraco. (Isto de manhãzinha, no nascer do sol). Vêem-se as cascas de besouros comidos, ossos de cobra, etc. Ninguém gosta de passar ali, que é perigoso: espinho de cobra. (ROSA, 2OII, p. 83).

Partindo do mundo fenomenológico para a ficção, a avifauna volita em todas as direções interpretativas da obra como um elemento muito bem estudado e cuidadosamente representado. Essa relação foi por nós exemplificada através das anotações de campo e é reforçada quando analisamos a correspondência que o autor mantinha com os seus tradutores, em que expressa a preocupação para que a representação mantenha sua profundidade e verossimilhança. $\mathrm{Na}$ troca de informações sobre as novelas que compõem Corpo de baile, publicado no mesmo ano de Grande sertão: veredas, o tradutor italiano pergunta a Rosa o contexto do "orobó de um nhambú”, o que é respondido da seguinte forma:

Orobó: = traseiro, nádega, ânus, UROPÍGIO.

nhambu: $=$ (inambu) Ave galinácea dos Tinamídeos. Gracioso, pequeno, sem cauda, vive quase sempre em terra, só voando, raro, voo rasteiro.

“o orobó de um nhambú”; notar a aliteração, além da sonoridade cômica. (BIZZARRI, I972, p. 4I).

Há aqui uma responsabilidade enorme para Bizzarri. A preocupação com uma representação eficiente é demonstrada por Rosa, que revela, numa escala crescente,

7 Flan: o jornal da semana, n. I4. O vaqueiro e o ministro: o personagem fala sobre o autor, I2/7/I953. Consultado no Fundo João Guimarães Rosa, Arquivo do Instituto de Estudos Brasileiros da USP, código de referência JGR-Ro2,I72.

8 "Uma hora, revirou de correr atrás, agachado, feito pegador de galinha, tropeçando no bamburral e espichando tombo, só por ter percebido de relance, inho e zinho, fugido no balango de entre as moitas, o orobó de um nhambú" (ROSA, 2006, p. 393). 
o que está escondido no orobó: partindo do popular “traseiro”, passando para o formal "nádegas”, para o anatômico “ânus”, chegando finalmente no ornitológico "uropígio". Já o nhambu tem sua aparência descrita, seu jogo sonoro revelado. Há nesse exemplo uma demonstração do trabalho de artífice do autor mineiro que só é parcialmente revelado ao tradutor italiano. Muitos tinamídeos têm a coloração críptica, são pardos, mimetizando defensivamente o solo onde habitam, porém, em discordância com o resto de sua aparência, as penas de seu dorso inferior, as coberteiras, são ornamentadas. De acordo com Lima (2004), o nhambu, no caso o inhambu-chintã (Crypturellus tataupa) "é uma ave muito arisca, que, quando percebe um possível predador, agacha-se e levanta as penas da cauda, como se fosse uma flor desabrochada” (LIMA, 2004, p. 35). Essa característica é, inclusive, responsável pela nomenclatura da ave, uma vez que possui as coberteiras semelhantes (aos olhos interioranos) a um pano estampado de chita. O "orobó de um nhambu" representa a rebentação rasteira de uma ave em toda sua pluralidade semântica ligada a um conhecimento ecológico tradicional que lhe confere autonomia e complexidade simbólica; complexidade que se confirma diversas vezes nas correspondências, por vezes menos provenientes das observações imediatas do autor do que das abstrações causadas por elas:

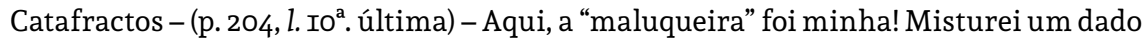
onomatopaico: a galinha-d'angola vive a gritar - Tou fraca! Tou frac'!... - com um significado tirado do latim: Cataphractus = encouraçado de ferro, vestido de armadura...; * por causa do aspecto da ave *. (BIZZARRI, I972, p. 33).

Já a tradução alemã do romance proporcionou um encontro inusitado em sua elaboração: Helmut Sick, renomado ornitólogo naturalizado brasileiro, auxiliou, a pedido de Rosa, o tradutor alemão Curt Meyer-Clason. Sick e Rosa estiveram presos, por ocasião da Segunda Guerra Mundial, em Ilha Grande, onde um tomou gosto pela literatura e o outro se resignou a observar, catalogar e descrever as espécies visíveis de sua cela - dentre as quais II espécies de cupins jamais antes catalogadas. Essas competências adquiridas e desenvolvidas no claustro foram empregadas na produção da versão germânica do Grande sertão: veredas, orientada de perto por Rosa, que, exímio falante de alemão, não deixava de opinar. Como exemplo disso temos diversos trechos das correspondências em que sugestões são dadas por Sick e Rosa para que Meyer-Clason tome a decisão definitiva. Também fica muito clara a preocupação do autor com alguns temas abordados através da evocação do mundo natural, como é o caso do Manuelzinho-da-crôa (batuíra-de-coleira, Charadrius collaris):

Agora, um ponto, para mim, efetivamente, importante. É a respeito do pássaro muitíssimo gracioso, muito lindo - o "manuelzinho-da-crôa" [...]. O célebre viajante e explorador inglês Captain RICHARD F. BURTON, que percorreu o Estado de Minas Gerais e desceu os rios Das-Velhas e São-Francisco, em canoa, assim se refere a ele, no seu importante livro "Explorations of the HIGHLANDS OF THE BRAZIL; with a full account of the gold and diamond mines" [...]. Por motivos de simpatia minha pessoal, para com esse pássaro, e, também, porque o manuelzinho-da-crôa, no livro, representa 
um dos "motivos", tomado como símbolo, a minha ideia era registrarmos seu nome como: Kleiner-Emmanuel-der-Sandbank [...]. Se for possível isto, ficarei muito alegre; e, penso, o nosso livro ficará graciosamente enriquecido. (ROSA, 2003, p. I2I-I22).

\section{Alguns Casos emblemáticos}

Neste capítulo final apresentaremos alguns casos específicos que chamaram nossa atenção para a análise ecocrítica da avifauna na obra. Os exemplos citados são apenas alguns entre muitos, eles estão expostos aqui com o intuito de popularizar as leituras ecologicamente conscientes não só da obra de Guimarães Rosa, mas da literatura em geral.

Começamos linearmente com um exemplo manifesto no início do romance, quando Riobaldo, diversamente de seu cavalo, escapa por um triz de um tiroteio, se esfolando e exaurindo todas as suas forças na fuga que descamba, por fim, na toca de um bicho que, para sorte do protagonista, logo se reconhece como uma irara (Eira barbara). Esse mustelídeo é um indicador biológico da ausência de cobras. Reconhecendo isso nosso protagonista se tranquiliza e, arfando no fundo do fosso, nos apresenta o seguinte relato:

Eu podia me largar. Eu era só mole, moleza, mas que não amortecia os trancos, dentro, do coração. Arfei. Concebi que vinham, me matavam. Nem fazia mal, me importei não. Assim, uns momentos, ao menos eu guardava a licença de prazo para me descansar. Conforme pensei em Diadorim. Só pensava era nele. Um joão-de-barro cantou. Eu queria morrer pensando em meu amigo Diadorim [...]. (ROSA, I956, p. 22).

Diadorim desponta repentinamente na memória e, após seu anúncio, vocaliza a ave prenunciando a conclusão fatalista. $O$ ato de "só pensar nele" seguido do canto produz uma imagem sutil relacionada a essa ave: o joão-de-barro (Furnarius rufus) pertence à família dos furnarídeos, dos quais existem diversas espécies com um comportamento comum - a vocalização conjunta, em pares, que está bem documentada em Sick (200I, p. 557): "O casal solta seu canto, forte grito ou gargalhada, frequentemente em conjunto, p. ex: Furnarius, Leptasthenura, Schizoeaca, Schoeniophylax, Certhiaxis cinnamomea, Cranioleuca trulpina, Phacellodomus, Anumbius, Lochmias, Pseudoseisura e Berlepschia”. Ciente da natureza desse pássaro tão emblemático do Brasil oriental, Rosa traz uma vocalização muito específica nessa digressão. Riobaldo encontra-se sozinho, desacorçoado de tudo e todos, Diadorim vem à memória junto com um canto que, máxime, é uma invocação, um chamado que apela para consonância do parceiro, ou como descreve Sick:

Voz: estridente "kí-kí-kí..." (canto); "krip” (chamada) em sequências rítmicas mais prolongadas como que um canto festivo, crescente e decrescente; o casal sincroniza um dueto (as estrofes do macho e fêmea são um pouco diferentes em altura e ritmo) cantando sobre ou ao lado do ninho de cabeça levantada, bico largamente aberto 
e sacudindo as asas meio descaídas e tremendo o corpo todo, mostrando a maior vivacidade. (SICK, 200I, p. 565).

Outra ave emblemática surge relacionada a Diadorim na ocasião da visita à Fazenda Santa Catarina. Com o aparecimento de Otacília na narrativa, fracionam-se os afetos e multiplicam-se as tensões, o amor intangível do protagonista se torna conflituoso assim que esse novo elemento surge e é anunciado, verbalizado por Riobaldo e vocalizado, nas profundezas notívagas da mata, pela mãe-da-lua (Nyctibius griseus):

- “Aquilo é poço que promete peixe...” - o Jesualdo disse. Dela devia de ser. - "Amigo, não toque no nome dessa moça, amigo!...” - eu falei. Ninguém deu resposta, eles viam que era a sério fatal, deviam de estar agora desqueixelados, no escuro. Por longe, a mãe-da-lua suspirou o grito: - Floriano, foi, foi, foi... - que gemia nas almas. Então, era que em alguma parte a lua estava se saindo, a mãe-da-lua pousada num cupim fica mirando, apaixonada abobada. Deitado quase encostado em mim, Diadorim formava um silêncio pesaroso. Daí, escutei um entredizer, percebi que ele ansiava raiva. De repente. - “Riobaldo, você está gostando dessa moça?”. (ROSA, I956, p. I49).

A inserção da ave aqui está ligada diretamente com a escolha terminológica empregada para traduzir a vocalização: “- Floriano, foi, foi, foi... - que gemia nas almas”. Da Bolívia à Bahia há diversos relatos folclóricos que tematizam especificamente essa ave, muitos deles foram registrados por Teschauer (I925) e revistos por Santos (I979), tendo em comum sempre a relação do canto melódico da ave com o lamento de uma figura feminina vítima de um amor impossível. A versão dos pataxós, relatada por Straube (2004), conta que um bacurau (Caprimulgidae sp.) iria se casar com a mãe-da-lua; por causa disso ele pediu uma pena de cada ave da floresta para a cerimônia, que, por uma peripécia interespécies, acaba não acontecendo, pois a boca descomunal da mãe-da-lua assusta o bacurau, que foge para nunca mais voltar. Esse mito empresta coerência à morfologia e à vocalização de ambas as espécies. O bacurau possui muitas penas com padrões singulares (como se pertencessem a diversos pássaros), que também são demasiadamente moles em comparação com outras espécies, o que atestaria sua artificialidade. Sua vocalização é descrita como "amanhã-eu-vou", nome pelo qual também é chamado em Minas Gerais e que é diretamente relacionado ao mito pataxó. Já a mãe-da-lua (Nyctibius griseus) tem sua boca abismal justificada, assim como o seu melancólico canto, que reconta seu infortúnio. A ligação do amor impossível com essa espécie é tão forte que não são incomuns no norte do país vassouras confeccionadas com as penas da mãe-da-lua, como relatado por Sick (200I, p. 408): "Para os matutos da Amazônia, as rêmiges e retrizes do urutau teriam o condão de proteger a castidade das meninas. Para tanto, a mãe varre debaixo das redes das filhas com uma vassoura confeccionada destas penas". Não é difícil relacionar o conhecimento mitológico agrilhoado a essa ave com a sua ocorrência no Grande sertão: veredas, quando Diadorim, impedida de se relacionar com Riobaldo, observa castamente enquanto este se afeiçoa a Otacília.

Como último exemplo escolhemos o japu (Psarocolius decumanus), mencionado sob o nome popular de joão-congo. O pássaro em questão pertence à família dos icterídeos, 
característicos por seu canto complexo. Essa ave joga-se para a frente no ato da vocalização, como numa reverência, por vezes indo até a metade do galho e retornando num impulso ao ponto inicial. Esse comportamento foi descrito por Tashian:

[...] o pássaro começa curvando-se para a frente em uma profunda reverência até que sua cabeça esteja bem abaixo do poleiro. Ao mesmo tempo, ele agita as penas do corpo e une as asas estendidas nas costas. As asas são então rapidamente vibradas com as primárias abertas. [...] Finalmente, o bater das asas para, e o pássaro sai de seu arco, todo o espetáculo durando cerca de quatro a cinco segundos. (TASHIAN, I957, p. 94 tradução nossa)?.

Esse movimento de retorno alia-se ainda a uma vocalização que soa como um som ao inverso. Essa imagem, singularíssima em sua multiplicidade, ocorre em um trecho onde há a repetição contínua de vocábulos que apontam para o regresso:

Pelo que, do trecho, voltamos. Para mais poente do que lá, só uruburetamas. E o caminho nosso era retornar por essas gerais de Goiás - como lá alguns falam. $\mathrm{O}$ retornar para estes gerais de Minas Gerais. Para trás deixamos várzeas, cafundão, deixamos fechadas matas. O joão-congo piava cânticos, triste lá e ali em mim. (ROSA, I956, p. 5I9-negritos nossos).

A combinação dos vocábulos que Rosa escolhe assevera os hábitos repetitivos do japu, o eterno retorno, canto após canto, surgindo no meio da espiral narrativa de Riobaldo. Tal encontro de dois personagens num contínuo processo de regressão só é possível graças ao esforço de Rosa em aliar o conhecimento popular com a ciência natural.

\section{CONSIDERAÇõES FINAIS}

A ecologia já foi assimilada pelo vocabulário do século XXI. Reconhece-se como uma matéria hegemonicamente deliberada pelas ciências naturais que, de acordo com Evernden (I978, p. 93), restringem-se em sua maioria a pensar no meio ambiente como uma fonte de recursos que devem ser manejados com responsabilidade. Não é preciso muita imaginação para problematizar os efeitos dessa relação sujeito-objeto nas espécies e biomas que não são, ao menos visivelmente, pragmáticos para o homem ou financeiramente quantificáveis. Quando o movimento ecológico cria o seu discurso pautado no pragmatismo ele cai na arapuca (do tupi wira, ave; púka, rebentar) da sustentabilidade, da gestão ambiental e de outras formas antropocêntricas de se relacionar com o meio ambiente. O presente trabalho se inspirou no conhecimento ecológico expresso no único romance publicado por Guimarães Rosa para ressaltar

9 No original: "[...] the bird begins by bending forward in a deep bow until his head is well below the perch. At the same time he ruffles his body feathers and brings the extended wings together over the back. The wings are then vibrated rapidly with the primaries open. [...] Finally, the wing flapping stops and the bird comes out of his bow, the entire performance lasting about four to five seconds”. 
a riqueza e autonomia da natureza, tão privilegiada pela sensibilidade e curiosidade imensurável do autor mineiro que buscou na cosmologia ameríndia, na ciência matuta, no jargão do boiadeiro e no tratado de zoologia uma coleção de relatos tão plural que cria uma epopeia à parte, concomitante à travessia de Riobaldo. A nosso ver, a linguagem de Rosa vai ao encontro da proposta moderna da ecocrítica, expressa por Manes (I992, p. 26) quando este afirma ser necessário aprender não somente uma nova ética, mas também uma nova linguagem livre dos direcionamentos humanistas, que seja descentralizada, pós-humanista e ecologicamente humilde. Oelschlaeger (I992, p. 27I-272) afirma que a linguagem é ao mesmo tempo nosso fator alienante e a chave para uma nova relação com o mundo natural. Grande sertão: veredas, com sua linguagem revolucionária, nos parece uma obra inaugural na busca de uma "gramática ecocrítica" na literatura brasileira.

\section{SOBRE OS AUTORES}

WILLIAN DOLBERTH é mestrando, com auxílio da Coordenação de Aperfeiçoamento de Pessoal de Nível Superior (Capes), no Programa de Pós-Graduação em Letras da Universidade Federal do Paraná (UFPR), na linha de literatura e outras linguagens.

E-mail: wdolberth@gmail.com

https://orcid.org/0000-0003-0I74-5955

KLAUS F. W. EGGENSPERGER é professor de Estudos Literários e Culturais da graduação e da pós-graduação em Letras na UFPR, onde fundou o Grupo de Estudos Ecocríticos (Geco), e autor de, entre outros trabalhos, Modale Nebenverben im Jiddischen. Eine korpusgestützte Untersuchung zu "soln" und "wolt" (I995).

E-mail: klausegge@gmail.com https://orcid.org/oooo-0003-4484-8874

\section{REFERÊNCIAS}

BARROS, Manoel de. A desconstrução das palavras. Entrevista concedida a Ana Accioly. Terceiro Mundo, n. I75, julho, I994, p. I7-I9. Disponível em: <http://repositorio.im.ufrrj.br:8080/jspui/bitstream/I2358I3/260/I/CTM_EdicaoBrasileira_Ano_NumeroI75_ooo_Completa.pdf $\rangle$. Acesso em: ago. 2019 . 
BIZZARRI, E. João Guimarães Rosa: correspondência com o tradutor italiano. São Paulo: Instituto Cultural Ítalo-Brasileiro, I972.

DESCOURLITZ, J. T. História natural das aves do Brasil (ornitologia brasileira). Belo Horizonte: Itatiaia, I983.

DURÃES, F. S. O mito de Fausto em Grande sertão: veredas. Rio de Janeiro: Academia Brasileira de Letras, I999.

EGBERT, M. L. The life of birds in literature. Trier: Wissenschaftlicher Verlag, 2015.

EVERNDEN, Neil. Beyond ecology: self, place, and the pathetic fallacy. In: GLOTFELTY, C.; FROMM, H. (Ed.). The ecocriticism reader: landmarks in literary ecology. Athens: University of Georgia Press, I996, p. 92-I04.

FROMM, H. (I978). From transcendence to obsolescence In: GLOTFELTY, C.; FROMM, H. (Ed.). The ecocriticism reader: landmarks in literary ecology. Athens: University of Georgia Press, I996, p. 30-39.

GLOTFELTY, C.; FROMM, H. (Ed.). The ecocriticism reader: landmarks in literary ecology. Athens: University of Georgia Press, I996, p. 30-39.

LIMA, P. C. Aves da pátria da Leari. Salvador, Atualidades Ornitológicas n. I28, nov.-dez. de 2005.

MANES, C. Nature and Silence. In: GLOTFELTY C.; FROMM, H. (Ed.). The ecocriticism reader: landmarks in literary ecology. Athens: University of Georgia Press, I996, p. I5-29.

MEYER, Mônica. Ser-tão natureza: a natureza em Guimarães Rosa. Belo Horizonte: Editora UFMG, 20I7.

MOREIRA, P. Modernismo localista das Américas: os contos de Faulkner, Guimarães Rosa e Rulfo. Belo Horizonte: Editora UFMG, 2012.

OELSCHLAEGER, M. Wilderness, civilization and language. In: (Ed.). The wilderness condition: essays on environment and civilization. San Francisco: Sierra Club Books, I992.

RÓNAI, P. (Seleção e prefácio). Rosiana: uma coletânea de conceitos, máximas e brocardos de João Guimarães Rosa. Rio de Janeiro: Salamandra, I983.ROSA, J. G. Grande sertão: veredas. I. ed. Rio de Janeiro: José Olympio, I956.

. João Guimarães Rosa: correspondência com seu tradutor alemão Curt Meyer-Clason (I958-1967). Belo Horizonte: Editora UMFG, 2003. . Corpo de baile. Rio de Janeiro: Nova Fronteira, 2006. . A boiada. Rio de Janeiro: Nova Fronteira, 20II.

SANTOS, E. Da ema ao beija-flor (vida e costumes das aves do Brasil). Belo Horizonte: Itatiaia, I979.

SICK, H. Ornitologia brasileira. Edição revista e ampliada por José Fernando Pacheco. 3. ed. Rio de Janeiro: Nova Fronteira, 200I.

SIGRIST, T. Aves do Brasil oriental. Guia de bolso. São Paulo: Avis Brasilis, 20I4.

STRAUBE, F. C. Urutau: ave-fantasma. Atualidades Ornitológicas n. I22, nov.-dez. 2004.

TASHIAN, R. E. Nesting behavior of the Crested Oropéndola (Psarocolius decumanus) in Northern Trinidad. Zoologica: New York Zoological Society v. 42, issue 8, I957, p. 87-98.

TESCHAUER, C. Avifauna e flora nos costumes, superstições e lendas brasileiras e americanas (estudos ethnologicos). 3. ed. completa. Porto Alegre: Livraria Globo, I925.

TÜÜR, K. Bird sounds in nature writing: human perspective on animal communication. Sign Systems Studies, n. 37 (3/4), University of Tartu Press, 2009, p. 580-6I3.

VAN PERLO, B. A field guide to the birds of Brazil. New York: Oxford University Press, 2009.

WikAves. Observação de aves e ciência cidadã para todos. Disponível em: <https://www.wikiaves.com. br/wiki/elaenia>. Acesso em: ago. 20I9. 